\title{
Changing a paradigm : PTA is more important than the residual stromal bed as a risk factor for post -LASIK ectasia
}

\author{
Mudando um paradigma: PTA é mais importante que o leito \\ residual como fator de risco para ectasia pós-LASIK
}

\section{Corneal ectasia and its mysteries}

Corneal ectasia after laser in situ keratomileusis (LASIK) is a complicationcharacterised by progressive corneal thinning and bulging, which may lead to significant visual loss. While most patients who develop post-LASIK ectasia present identifiable risk factors, especially preoperative changes on corneal topography with a Placido disc, ectasia in patients with normal preoperative tests is still a mistery. ${ }^{1,2}$ This editorial presents a new risk factor called Percentage ofTissue Altered,or PTA.Previous studies conducted by me and my colleagues demonstrated that PTA has a higher correlation with the risk of ectasia than other factors already established in the literature, such as residual stromal bed. ${ }^{3-11}$ Improving the understanding, acceptance and recognition of risk factors for ectasia after refractive surgery is essential to reduce the incidence of this adverse effect.

In simple terms, post-LASIK ectasia is a change in the biomechanical integrity of the cornea which exceeds the threshold required to maintain its curvature and shape.In theory, this can happen in three different scenarios: 1)When a cornea that is already prone to developing ectasia is subjected to surgery; 2) when a weaker but clinically stable cornea is subjected to surgery; 3 ) when a relatively normal cornea is weakened by surgery, exceeding its safety threshold.Our research is focused on the latter scenario.

\section{A new measure:PTA}

There is a relationship between corneal thickness, flap thickness and ablation depth, which determine the biomechanical changes occurring after LASIK. The tensile strength of the cornea is not uniform throughout its central thickness, with progressive weakening in the posterior two thirds.This influences the degree of biomechanical impairment after refractive surgery, with flap thickness and ablation depth playing a significant role in postoperative weakening. ${ }^{12}$ We have proposed and investigated a new measure, PTA, which is a better parameter to describe the postoperative effects on the cornea. For LASIK, PTA is derived from the following equation: $\mathbf{P T A}=\mathbf{( F T}+\mathbf{A D}) / \mathbf{C C T}^{3-5}$ where FT $=$ flap thickness, $\mathrm{AD}=$ ablation depth, and $\mathrm{CCT}=$ central corneal thickness. This is a more accurate measure of the risk of ectasia than any of its individual components.

\section{Concept of risk factor}

The main objective of risk assessment is not to determine who will develop ectasia, but to use rigorous, adequate scientific methods to determine who has a higher chance of developing it.There is a crucial difference between the prevalence of a risk factor in a group and the influence of such factor in that group.The former refers to the number of individuals in the group who have such factor, while the latter is related to something that could occur in the group when exposed to such factor. ${ }^{1}$

Prevalence analysis is insufficient to investigate a risk factor.The appropriate tool to investigate the association between a risk factor and the occurrence of an event is the odds ratio.This is the chance of an outcome or event in the presence of a particular factor compared to the chance in the absence of such factor. As this is a ratio, values $>1$ indicate that this is a risk factor, while values $<1$ indicate it is a protective factor.

\section{PTA: a new, scientifically validated risk factor}

1. Our studies provide sufficient scientific evidence that a high PTA, especially above $40 \%$, is significantly associated with the development of ectasia in patients with normal preoperative corneal topography.Our analysis has also shown that a high PTA is a more important indicator of risk than previously known factors, such as residual stromal bed.-5

Compared to other risk factors, such as a thin residual stromal bed, low central corneal thickness, young age, and high myopia, a high PTA is not only more prevalent in patients with ectasia, but also shows a higher odds ratio and increased prognostic ability for ectasia, based on logistic regression.Furthermore, a high PTA is more strongly associated with the risk of ectasia than any of its individual components, including ablation depth (high myopia), central corneal thickness, and, indirectly, residual stromal bed.Our research group was the first in the world to specifically investigate the concept of PTA and its role in post-LASIK ectasia. ${ }^{3-5}$

Our long line of research has also shown that:

2. When used in various screening tools, PTA significantly increases the sensitivity of risk detection.Our research group is currently publishing further studies that show validated ways to employ these new methods for screening patients at risk. 
3. In patients who have changes on corneal topography with a Placido disc, whether minimal or highly indicative of the risk for post-LASIK ectasia, PTA values associated with ectasia are significantly lower than the value of e" $40 \%$ associated with ectasia in patients with a normal topography.This shows that in patients with preoperative topographic changes, the PTA threshold for biomechanical imbalance is lower. ${ }^{3-11}$

In conclusion, our studies have shown that PTA is currently the most effective predictorof the risk for post-LASIK ectasia, especially in eyes with a normal topography, and it is also an important additional indicator in eyes with preoperative abnormalities. This represents an important step forward in the field of refractive surgery, as PTA is emerging as an effective tool in the screening of patients, thus significantly decreasing the chance of ectasia after refractive surgery.

Marcony R. Santhiago Federal University of Rio de Janeiro, Rio de Janeiro/RJ, Brazil; São Paulo University, São Paulo/SP, Brazil

\section{REFERENCES}

1. Randleman JB, Russell B, Ward MA, Thompson KP, Stulting RD. Risk factors and prognosis for corneal ectasia after LASIK. Ophthalmology. 2003;110(2):267-275.

2. Randleman JB, Woodward M, Lynn MJ, Stulting RD. Risk assessment for ectasia after corneal refractive surgery. Ophthalmology. 2008;115(1):37-50.

3. Santhiago MR, Smadja D, Gomes BF, Mello GR, Monteiro ML, Wilson SE, Randleman JB. Association between the percent tissue altered and post-laser in situ keratomileusis ectasia in eyes with normal preoperative topography. Am J Ophthalmol. 2014;158(1):87-95.e1.

4. Santhiago MR, Wilson SE, Hallahan KM et al. Changes in custom biomechanical variables after femtosecond laser in situ keratomileusis and photorefractive keratectomy for myopia. J Cataract Refract Surg. 2014;40(6):918-28.

5. Santhiago MR, Kara-Junior N, Waring GO 4th. Microkeratome versus femtosecond flaps: accuracy and complications. Curr Opin Ophthalmol. 2014;25(4):270-4.

6. Santhiago MR. Common Warning Signs of High-Risk Eyes. Cataract Refract Surg Today. 2014; (Mar):18-19.

7. Santhiago MR, Smadja D, Mello G, Wilson SE, Randleman JB. Role of percentage of tissue altered as risk factor for ectasia after LASIK in eyes with normal preoperative topography. Paper presented at: the 2014 ASCRS meeting; April 25-29, 2014; Boston. (Best Paper award).

8. Santhiago MR, Smadja D, Mello G, Wilson SE, Randleman JB. Role of Percentage of Tissue Altered (PTA) as a risk factor in eyes with Normal preoperative topography that developed Ectasia after LASIK. In: ARVO Meeting 2014; 2014, Orlando, FL. IOVS, 2014. v. 55. p. 1548-9.

9. Santhiago MR, Smadja D, Mello G, Wilson SE, Randleman JB. Role of PTA as risk factor for ectasia after LASIK in eyes with normal and suspicious preoperative topography. Paper presented at: the 2014 AAO Meeting; Oct 17-21, 2014; Chicago.

10. Santhiago MR. Refractive surgery problem: Consultation Section. J Cataract Refract Surg. 2013;39(12):1933-4.

11. Santhiago MR, Wilson SE Cellular effects after laser in situ keratomileusis flap formation with femtosecond lasers. Cornea. 2012;31(2):198-205.

12. Randleman JB, Dawson DG, Grossniklaus HE, McCarey BE, Edelhauser HF. Depth-dependent cohesive tensile strength in human donor corneas: implications for refractive surgery. J Refract Surg.2008;24(1):S85-9. 